\title{
Análise de fornecimento de produtos da agricultura familiar para o Programa Nacional de Alimentação Escolar (PNAE) no município de São Gabriel-RS
}

\author{
Analysis of products supply from farming family for the National School feeding \\ Programme (PNAE) are in the Municipality of São Gabriel-RS

\begin{abstract}
Alex Cesar Cavalheiro Marques, Ana Júlia Senna Sarmento Barata e Ricardo Ribeiro Alves
\end{abstract}
Universidade Federal do Pampa, São Gabriel-RS, Brasil

alexmarques.ufp@gmail.com; anasenna@unipampa.edu.br; ricardoalves@unipampa.edu.br

\begin{abstract}
Resumo
Através do Programa Nacional de Alimentação Escolar (PNAE) e do Programa de Aquisição de Alimentos (PAA) o Estado busca implantar uma Política Pública com a finalidade de fomentar a agricultura familiar proporcionando oportunidades de distribuição aos agricultores atendendo às necessidades alimentares dos alunos das escolas públicas. O trabalho objetiva analisar o fornecimento de produtos da agricultura familiar em São Gabriel/RS para o PNAE e verificar a efetividade desta politica na esfera municipal. A pesquisa foi exploratória e teve abordagem qualitativa. Elaborou-se um referencial teórico e realizou-se visitas in loco e entrevistas semi-estruturadas com gestores públicos e agricultores familiares. Os resultados obtidos revelaram que o processo de suprimento contempla poucos agricultores e não atinge a meta prevista em lei.
\end{abstract}

Palavras-chave: Políticas Públicas. Programa de Aquisição de Alimentos. Produção. Distribuição de alimentos.

\begin{abstract}
Through the National School Food Program (PNAE) and the Food Acquisition Program (PAA) the State seeks to deploy a Public Policy in order to promote family farming providing distribution opportunities for farmers meeting the food needs of public school students. The work aims to analyze the supply of products from family farms in San Gabriel / RS for the PNAE and verify the effectiveness of this policy at the municipal level. The research was exploratory and had a qualitative approach, development of theoretical framework, site visits and construction and application of semistructured interviews with public officials and family farmers. The results revealed that the supply process includes few farmers and does not reach the goal set forth by law.
\end{abstract}

Keywords: Public Policy. Food Acquisition Program. Production. Distribution of food. 


\section{Introdução}

O surgimento crescente de necessidades básicas da população faz com que o Estado foque, cada vez mais, seus esforços em ações que supram o interesse coletivo, direcionando sua efetividade no atendimento do bem comum. Com o objetivo de atender essas necessidades e demandas, o poder público precisa valer-se de ferramentas sociais que são operacionalizadas através de políticas públicas.

O Estado precisa suprir demandas institucionais, principalmente no setor educacional, elaborando políticas públicas que visem, por exemplo, à adequada alimentação escolar. Por outro lado, existe uma preocupação constante no que diz respeito aos fornecedores destes alimentos. Assim, os gestores públicos precisam atender às necessidades alimentares dos alunos das escolas públicas e, paralelamente, fomentar o desenvolvimento econômico e social, propor-cionando oportunidades de negociação com cooperativas, agricultores e comércio local.

O presente trabalho tem como objetivo analisar o fornecimento de produtos da agricultura familiar em São Gabriel/RS para o Programa Nacional de Alimentação Escolar (PNAE); apurar: métodos de produção, dificuldades na distribuição de alimentos, possibilidades de melhorias e verificar a efetividade desta política na esfera municipal.

\section{Referencial teórico}

\subsection{Políticas públicas}

Políticas Públicas se materializam na forma de programas, projetos, leis, campanhas publicitárias, rotinas administrativas, gastos públicos, entre outros (SECCHI, 2013). Desta forma, o Estado deve ser provedor de políticas públicas e de um aparato legal que regule as ações humanas (BATALHA, 2009).
As políticas públicas objetivam o bem comum. Segundo Rua (2009, p. 20), “por mais óbvio que possa parecer, as políticas públicas são públicas”. A autora explicita que, embora as políticas públicas incidam sobre a esfera privada (família, mercado, religião), elas não são privadas, pois mesmo que as entidades privadas participem de sua formulação ou implementação, a possibilidade de realização de suas ações está amparada em decisões públicas, decisões tomadas por agentes governamentais, com base no poder imperativo do Estado.

Nessa perspectiva, programas públicos alimentares, como o PNAE, aparecem como possibilidade de auxiliar no enfrentamento das problemáticas referentes ao consumo e a produção de alimentos. Consegue-se contemplar por um lado à saúde da comunidade escolar e, de outro, cria-se mercados para os agricultores locais, fomentando boas práticas ambientais (VILLA REAL; SCHNEIDER, 2011).

\subsection{Programa Nacional de Alimentação Escolar (PNAE) e a valorização da agricultura familiar}

O PNAE é uma ação do governo federal que garante a alimentação escolar a todos os estudantes dos ensinos infantil, fundamental e médio das escolas públicas e filantrópicas. Isso acontece por meio do Fundo Nacional de Desenvolvimento para a Educação (FNDE), que repassa os recursos financeiros para todos os estados e municípios (MDA, 2014).

No ano de 2003 foi instituído o Programa de Aquisição de Alimentos (PAA), cujo objetivo principal foi fomentar e fortalecer a agricultura familiar, compreendendo um conjunto de ações relativas à aquisição da produção agropecuária e sua conseqüente distribuição para grupos de pessoas vulneráveis, contribuindo para a formação dos estoques estratégicos de alimentos do país (MATTEI, 2007). 
A partir de 2009, o PNAE visou ser um programa de alimentação escolar saudável para o universo da rede pública de educação básica e de jovens e adultos e também estabeleceu que no mínimo 30\% dos repasses do PNAE sejam investidos na aquisição de produtos da agricultura familiar (PEIXINHO, 2013).

Essa articulação das compras de alimentos do Programa Nacional de Alimentação Escolar com os produtos advindos da agricultura familiar traz inúmeras vantagens para a promoção do desenvolvimento rural e da educação: transferência de renda diretamente aos agricultores do entorno com as compras locais; a aproximação entre os agricultores de alimentos com os consumidores - no caso, os alunos das escolas adquirentes, possibilidade de fortalecer circuitos locais de produção, propiciando o aquecimento da economia local e regional (VILLA REAL; SCHNEIDER, 2011).

Além disso, o estímulo às compras de gêneros alimentícios de agricultores familiares contribui para que esses agricultores se organizem cada vez mais e qualifiquem suas ações comerciais, beneficia os escolares mediante produtos que atendam às necessidades nutritivas exigidas, incentiva o mercado produtivo local, além de promover o desenvolvimento local de forma sustentável. O Desenvolvimento Local Sustentável baseia-se na promoção de processos que diminuam a pobreza e as desigualdades ao mesmo tempo em que consigam proteger o meio ambiente dos impactos decorrentes dos processos de crescimento econômico (TURPIN, 2008).

A preocupação com a segurança alimentar e nutricional entre os alunos das escolas públicas subsidiou a criação da Lei 11.947 de 2009 que trata da Alimentação Escolar. Esta Lei prevê o apoio ao desenvolvimento sustentável, com incentivos para a aquisição de gêneros alimentícios diversificados, produzidos em âmbito local e preferencialmente pela agricultura familiar e pelos empreendedores familiares rurais, priorizando as comunidades tradicionais indígenas e de remanescentes de quilombos.
Vislumbram-se, com isto, o início de um modelo de desenvolvimento que promove não só crescimento econômico como também justiça social, conservação ambiental e saúde pública (TRICHES, SCHNEIDER, 2010).

\subsection{Agricultura familiar}

A agricultura familiar possui como fundamentos principais a gestão feita pela família, sendo seu trabalho preponderante, e a possibilidade de um modo de produção sustentável (socialmente mais justo e ambientalmente equilibrado), que garanta a preservação do estabelecimento, passado de geração em geração (TURPIN, 2008).

A agricultura familiar, segundo Veiga (2001), apresenta as seguintes características organizacionais:

- trabalho e gestão intimamente relacionados;

- direção do processo produtivo diretamente assegurada pelos proprietários ou arrendatários;

- $\quad$ ênfase na diversificação;

- $\quad$ ênfase na durabilidade dos recursos e na

qualidade de vida;

- trabalho assalariado complementar e;

- decisões imediatas adequadas ao alto grau de imprevisibilidade do processo produtivo.

O PRONAF (Programa Nacional de Fortalecimento da Agricultura Familiar) utiliza quatro critérios para definir agricultura familiar: predomínio da mão de obra familiar, área até quatro módulos fiscais, residência no estabelecimento ou em aglomerado próximo, e renda.

A maior diversidade de cultivos na agricultura familiar se deve à busca de diferentes rendas, distribuídas ao longo do ano, a procura do auto-consumo alimentar, a redução de riscos e a busca de uma menor dependência de insumos externos; assim apresentando sistemas diversificados mais próximos dos ecossistemas em que estão inseridos (BOTELHO FILHO, 2005). 
Segundo demonstram os dados IBGE no Quadro 1, no município de São Gabriel há uma parcela significativa de estabelecimentos de agricultura familiar, que constitui cerca de $60 \%$ dos estabelecimentos locais (SANTOS, 2011).

Quadro 1 - Estabelecimentos e área da agricultura familiar, País, UF, Município - 2006

\begin{tabular}{|c|c|c|c|c|}
\hline País, UF, Município & \multicolumn{2}{|c|}{ Agricultura familiar - Lei $\mathrm{n}^{\circ} 11.326$} & \multicolumn{2}{c|}{ Não familiar } \\
\hline & Estabelecimentos & Área (ha) & Estabelecimentos & Área (ha) \\
\hline Brasil & 4366267 & 80102694 & 809369 & 253577343 \\
\hline Rio Grande do Sul & 378353 & 6158610 & 63119 & 14168104 \\
\hline São Gabriel & 1026 & 27835 & 679 & 382128 \\
\hline
\end{tabular}

Fonte: Censo Agropecuário do IBGE, 2006.

Em função da importância da agricultura familiar no município de São Gabriel/RS e da necessidade de adoção de estratégias mais sustentáveis de comercialização, buscou-se avaliar o fornecimento de produtos da agricultura familiar em São Gabriel/RS para o PNAE e verificar a efetividade desta política na esfera municipal.

\section{Metodologia da pesquisa}

No intuito de atender o objetivo inicialmente realizou-se contato com instituições como: Secretaria da Educação do município e EMATER/RS com a finalidade de verificar a efetividade das Políticas Públicas voltadas à alimentação escolar e coletar informações sobre os fornecedores de alimentos para tal finalidade. $\mathrm{Na}$ seqüência, realizaram-se entrevistas semi-estruturadas com agricultores familiares, com a finalidade de obter informações sobre as Políticas Públicas e o PNAE, métodos de produção, dificuldades na distribuição de alimentos, valoração e possibilidades de melhorias.

Dentro deste contexto, a pesquisa pode ser classificada como exploratória, pois de acordo com Gil (2007) este tipo de pesquisa objetiva proporcionar maior familiaridade com o problema, com vistas a torná-lo mais explícito ou a construir hipóteses.

A pesquisa utilizou uma abordagem qualitativa que segundo Leal (2006) envolve ouvir as pessoas, explorando suas idéias e preocupações sobre determinado assunto, analisando os temas, buscando interpretá-los.
As principais etapas envolvidas na pesquisa foram:

1. Elaboração de referencial teórico sobre políticas públicas, PNAE e agricultura familiar;

2. Análise do Edital 001/2014 da Prefeitura Municipal de São Gabriel, lançada no mês de julho do ano de 2014;

3. Construção de roteiro de entrevistas, articulado com o referencial teórico, contendo quinze questões;

4. Entrevista na Secretaria de Educação do Município com intuito de verificar informações referentes ao suprimento de merenda escolar das escolas municipais;

5. Visita in loco a agricultores familiares, junto com o técnico da Emater, onde buscou-se mapear os agricultores que fornecem alimentos com a merenda escolar das escolas municipais;

6. Realização de entrevistas com três agricultores que abastecem a merenda escolar das escolas municipais. Foram selecionados esses três agricultores em vista que o Edital 001/2014 habilitou apenas sete agricultores. Porém, apenas três efetivamente comercializaram seus produtos. Por isso, esses foram selecionados. As entrevistas foram realizadas no primeiro semestre do ano de 2015.

\section{Resultados e discussão}

O Programa de Aquisição Alimentar no município de São Gabriel é centralizado e terceirizado. O 
órgão fiscalizador considerou que a compra terceirizada não atendia o item compra de agricultura familiar, com isso a Prefeitura passou a realizar a compra através de chamada pública. Sendo assim, a merenda escolar tornouse um canal de comercialização para agricultura familiar em São Gabriel.

O cadastro de agricultores para o DAP (Declaração de Aptidão ao PRONAF) é realizado pela EMATER/RS. No ano de 2014, havia vinte e seis agricultores cadastrados e cerca de cinquenta produtos que poderiam atender o PNAE, abastecendo hortifrutigranjeiros.

Segundo informações da Secretaria Municipal da Educação a Chamada Pública n. ${ }^{\circ}$ 001/2014 habilitou sete agricultores para fornecerem alimentos para a merenda escolar municipal. Destes, apenas três agricultores efetivamente comercializaram produtos.

Dos agricultores entrevistados, dois pertencem à Associação dos Moradores do Cerrito, Ambrósio e Pavão; ambos tem sua propriedade localizada no Rincão dos Ambrósios e apesar disto realizaram o fornecimento de forma individual. Já o Agricultor 1(P1) não pertence a nenhuma associação e possui sua propriedade no assentamento Conquista do Caiboaté, declarou que tem intenção de formar uma Associação com outros agricultores do assentamento.

Tais dados podem ser verificados no Quadro 2.

Quadro 2. Agricultores entrevistados no Município de São Gabriel/RS

\begin{tabular}{|c|c|c|}
\hline Agricultor & Localização da propriedade & Pertence a alguma associação \\
\hline P1 & Assentamento Conquista do Caiboaté & Não \\
\hline P2 & Rincão dos Ambrósios & Sim \\
\hline P3 & Rincão dos Ambrósios & Sim \\
\hline
\end{tabular}

Os agricultores informaram que recebem as informações da chamada pública através de contatos com Associações, Secretarias do Município, rádio e EMATER.

Conforme P1, ele já tinha a intenção de vender para a CONAB - Companhia Nacional de Abastecimento (também um órgão público). $\mathrm{Na}$ esfera municipal, o primeiro contato aconteceu através da nutricionista da Prefeitura e depois por uma Chamada Pública divulgada pelo rádio.

No perímetro urbano são sete escolas e creches que recebem produtos. Já na zona rural apenas uma escola é abastecida, a Escola Ernesto José Annoni. A freqüência de distribuição dos produtos nas escolas não é unificada e pode ser semanal, quinzenal, ou apenas uma vez de acordo com a disponibilidade de cada agricultor. Os principais produtos distribuídos são hortaliças e legumes: tomate, cebola, repolho, alface, beterraba e mandioca.
O transporte dos alimentos até as escolas ocorreu através do ônibus escolar da Prefeitura Municipal ou de veículo próprio. Questionados sobre a importância de uma central de recebimento para a distribuição, as respostas indicaram as seguintes vantagens: facilitaria a entrega, ganhar-se-ia tempo, diminuir-se-iam os custos, principalmente, se os agricultores estiverem organizados em Associações.

O município de São Gabriel, segundo dados do IBGE de 2010, possui área de 5.023,821 $\mathrm{km}^{2}$. As distâncias entre as áreas rurais e a sede administrativa do município e o péssimo estado de conservação das rodovias dificultam o transporte e a logística e são determinantes na distribuição da produção.

Além das despesas com sementes, o preparo do solo representa o maior custo para o agricultor, devido aos custos com combustível, máquinas e mão-de-obra. Com relação aos produtos usados para adubação, dois agricultores revelaram que utilizam adubos orgânicos. 
Apenas um utiliza produtos químicos, embora saliente que tem a intenção de fazer tratamento orgânico.

A assistência técnica ainda não é efetiva, mas a EMATER/RS tem colaborado com o cadastro, a divulgação e as orientações para o preenchimento de requisitos e documentos necessários para inclusão de agricultores na chamada pública.

As principais dificuldades apontadas pelos agricultores foram: logística e transporte, atender os requisitos de sanidade (produção de pães) e o período da chamada pública que prejudicou a entrega de alguns produtos que perderam a qualidade aceitável.

Os agricultores sugeriram como melhorias necessárias no processo: a criação de uma Central de Distribuição, a disponibilização da Prefeitura com serviços de máquinas, maiores investimentos em irrigação e apoio para organização de Associações. As melhorias mencionadas pelos agricultores estão de acordo com as formas de apoio ao produtor familiar pela merenda escolar descritas por Turpin (2009, p. 29) e relacionadas no Prêmio Gestor Eficiente da Merenda Escolar, onde o apoio em infra-estrutra produtiva e logística e o estímulo e capacitação para Cooperativismo e Associativismo são considerados mecanismos de incentivo a pequena produção.

No Quadro 3, são apontadas as escolas atendidas pelos agricultores familiares, as principais dificuldades encontradas e as melhorias que se fazem necessárias para maior eficácia do processo de fornecimento de produtos da agricultura familiar.

Quadro 3. Síntese dos resultados das entrevistas com agricultores

\begin{tabular}{|c|c|c|c|}
\hline Agricultor & Escolas atendidas & Principais dificuldades & Melhorias necessárias \\
\hline P1 & 7 (Zona Urbana) & $\begin{array}{c}\text { Custo com máquinas e } \\
\text { transporte }\end{array}$ & $\begin{array}{c}\text { Central de distribuição, disponibilização de máquinas agrícolas, } \\
\text { investimentos em irrigação, apoio para organização de Associações }\end{array}$ \\
\hline P2 & $\begin{array}{c}\text { Escola Ernesto José } \\
\text { Annoni (Zona Rural) }\end{array}$ & $\begin{array}{c}\text { Atender os requisitos de } \\
\text { sanidade, período da chamada } \\
\text { pública }\end{array}$ & $\begin{array}{c}\text { Apoio para organão de Associações, central de distribuição, máquinas agrícolas } \\
\text { cessán de }\end{array}$ \\
\hline P3 & $\begin{array}{c}\text { Escola Ernesto José } \\
\text { Annoni (Zona Rural) }\end{array}$ & $\begin{array}{c}\text { Atender os requisitos de } \\
\text { sanidade, período da chamada } \\
\text { pública }\end{array}$ & $\begin{array}{c}\text { Central de distribuição, cessão de máquinas agrícolas apoio } \\
\text { para organização de Associações }\end{array}$ \\
\hline
\end{tabular}

Fonte: Autores, 2015.

Apesar das dificuldades encontradas na produção, no transporte e no atendimento dos requisitos legais, os entrevistados destacaram que o suprimento de alimentos para as escolas públicas é vantajoso para o agricultor, pois garante a distribuição da produção excedente e complementa a renda mensal.

\section{Conclusões}

Através da análise do fornecimento de produtos da agricultura familiar na esfera municipal em São Gabriel/RS para o PNAE, verificou-se que a Chamada Pública N. ${ }^{\circ}$ 001/2014 contemplou poucos agricultores e não atingiu a meta para a aquisição de produtos da agricultura familiar.

As principais dificuldades apontadas pelos agricultores para o suprimento de alimentos para o setor público foram: atendimento aos requisitos de higiene e sanidade e o elevado custo com combustíveis, máquinas e transporte.

Os agricultores sugeriram como estratégias para melhoria no processo: a criação de uma central de distribuição; o maior apoio da Prefeitura através da disponibilização de serviços de máquinas, investimentos em irrigação e apoio para organização de Associações.

Em se tratando de conclusões mais definitivas sobre o PNAE como oportunidade de comércio para agricultura familiar e seus benefícios na cidade de São Gabriel - RS, a pesquisa precisaria ser ampliada ao longo do tempo, e, além disso, expandida para outras esferas como a estadual e federal, envolvendo no estudo outras instituições e agricultores. 


\section{Referências}

ALCANTARA, R. L. C.; SOUZA, A. P. O. Alternativas de mercado para a agricultura: a realidade dos produtos hortículas orgânicos no Brasil In: Batalha, M. O. Gestão do Agronegócio. São Carlos: EDUFSCAR, 2009.

BOTELHO FILHO, F. B. As portas de saída da pobreza e as estratégias da agricultura familiar para os negócios rurais In: Agricultura Familiar e Desenvolvimento Territorial - Contribuições ao Debate. Brasília: Universidade de Brasília. Centro de Estudos Avançados Multidisciplinares, Núcleo de Estudos Avançados. v.5. n. 17, 2005. p 131-140.

IBGE, Instituto Brasileiro de Geografia e Estatística. Censo Agropecuário 2006. Available from: http://www.ibge.gov.br/home/estatistica/economia/agrope cuaria/censoagro/2006_segunda_apuracao/default_tab_xl s.shtm.

GIL, Antonio Carlos. Como elaborar Projetos de Pesquisa. 4.ed. São Paulo: Atlas, 2007.

LEAL, A. E. M.; SOUZA, C. E. G. Construindo o Conhecimento pela Pesquisa: orientação básica para elaboração de trabalhos científicos. Santa Maria: Sociedade Vicente Pallotti, 2006.

MINISTÉRIO DO DESENVOLVIMENTO AGRÁRIO, Cartilha Orgânicos na Alimentação Escolar. Available from: http://www.fnde.gov.br/programas/alimentacaoescolar/alimentacao-escolar-material-de-

divulgacao/alimentacao-manuais/item/5240-cartilha-

orgânicos-na-alimentação-escolar.

MATTEI, L. Programa de aquisição de alimentos da agricultura familiar (PAA): antecedentes, concepção $e$ composição geral do Programa. Avaliação de políticas de aquisição de alimentos, n. 27, 2007. p. 33-44.

PEIXINHO, A. M. L. A trajetória do Programa Nacional de Alimentação Escolar no período de 2003-2010: relato do gestor nacional. Ciência \& Saúde Coletiva, 2013.18(4): p.909-916.

RUA, Maria das Graças. Políticas Públicas. Florianópolis: Departamento de Ciências da Administração/UFSC; [Brasília]: CAPES: UAB, 2009.
SECCHI, L. Políticas Públicas - Conceitos, esquemas de análise, casos práticos. 2. ed. Cengage Learning, 2013.168 p.

VEIGA, José Eli da. O Brasil rural precisa de uma estratégia de desenvolvimento. Brasília: Convênio FIPE IICA (MDA/CNDRS/NEAD) 2001.

VILLA REAL, L. C.; SCHNEIDER, S. O uso de programas públicos de alimentação na reaproximação do pequeno agricultor com o consumidor: o caso do programa de alimentação escolar. ESTUDO \& DEBATE, Lajeado, v. 18, n. 2, 2011. p. 57-79.

TRICHES, R. M.; SCHNEIDER, S. Alimentação Escolar e Agricultura Familiar: reconectando o consumo à produção. Saúde e Sociedade, São Paulo, v.19, n.4, 2010. p.933-945.

TURPIN, M. E. A Alimentação Escolar como Fator de Desenvolvimento Local por meio do Apoio aos Agricultores Familiares. Segurança Alimentar e Nutricional, Campinas, 16(2): 2009. p. 20-42. 